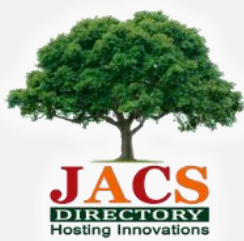

Journal of Nanoscience and Technology

Visit Journal at http://www.jacsdirectory.com/jnst
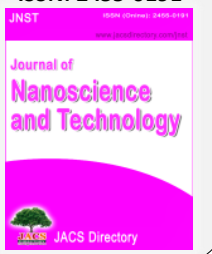

Special Issue on "International Conference on Nanomaterials - 2018" - Alagappa University

Issue Editor: Dr. G. Ramalingam

\title{
Spectroscopic Investigations of Undoped and Rare Earth Doped NLO Single Crystals of Manganese Mercury Thiocyanate Bis-Dimethyl Sulfoxide
}

\author{
L. Bhushan Kumar',*, E.V. Suresh Kumar², B. Yellamanda ${ }^{3}$, Y. Nirmal Rajeev ${ }^{4}$ \\ ${ }^{1}$ Dept. of Physics, SVKP College, Markapur - 523 316, AP, India. \\ ${ }^{2}$ Dept. of Chemistry, SVKP College, Markapur - 523 316, AP, India. \\ ${ }^{3}$ Dept. of Botany, SVKP College, Markapur - 523 316, AP, India. \\ ${ }^{4}$ Dept. of Physics, V. R. Siddhartha Engineering College, Kanuru - 520 007, AP, India.
}

\section{ART ICLE DETAILS}

Article history:

Received 21 March 2018

Accepted 29 March 2018

Available online 06 April 2018

\section{Keywords:}

Organo-Metallic Compounds

Crystal Growth

Spectral Studies

\begin{abstract}
A B S T RAC T
Good optical grade single crystals of pure, lanthanum $\left(\mathrm{La}^{3+}\right)$ and neodymium $\left(\mathrm{Nd}^{3+}\right)$ doped manganese mercury thiocyanate bis-dimethyl sulfoxide (MMTD) crystals are grown from aqueous solution by slow solvent evaporation technique at room temperature. Single crystal X-ray diffraction (XRD) data reveals that the grown crystals belong to the orthorhombic crystallographic system with the noncentrosymmetric space group P $2{ }_{1} 2{ }_{1} 2_{1}$. The crystals are characterized using optical absorption, Fourier transform infrared (FT-IR), Fourier transform Raman (FT-Raman), energy dispersive X-ray analysis (EDAX) studies. The second harmonic generation (SHG) efficiencies of the grown crystals are also measured using Kurtz and Perry powder technique. The nonlinear optical (NLO) activity of the pure MMTD significantly enhances due to rare earth dopants.
\end{abstract}

\section{Introduction}

The rapid growth in several important areas like microelectronics and communication technologies is due to the highly demanded progress in the field of crystal growth [1]. In spite of considerable research in this field, it is often considered as a fine combination of science, technology and art to grow new materials in single crystal forms at the optimum growth conditions [2]. An important aspect of utilizing organo-metallic structures for nonlinear optical applications is their unique charge transfer transitions, either from metal to ligand or from ligand to metal. Thiocyanate (SCN) is a highly versatile ligand with two terminal modes and thirteen multidentate bridging modes of coordination. Based on the concept developed by Pearson [3] on the hard and soft acids and bases rationalizes that soft cations show a pronounced affinity for coordination with softer ligands, while hard cations prefer coordination with harder ligands. The $\mathrm{SCN}$-ligands in $\mathrm{MnHg}(\mathrm{SCN})_{4}$ bridge the tetrahedrally coordinated $\mathrm{N}$-bonded $\mathrm{Mn}$ atoms and the tetrahedrally coordinated Sbonded $\mathrm{Hg}$ atoms into a 3-D network with the non-centrosymmetric space group. $\mathrm{MnHg}(\mathrm{SCN})_{4}$ has been identified to exhibit high hyperpolarizability due to the extended $\pi$-conjugation of the Mn-NCS-Hg bridges and their parallel alignments in the 3-D crystal structure [4].

Recent studies indicate that the Lewis-base adducts of these crystals have been identified to possess superior NLO property compared to their parent metal SCN crystals. The metal SCNs and their Lewis-base adducts are some of the interesting themes of structural chemistry [5]. This encouraging switch-over is mainly attributed to the enhancement in the NLO activity, by the addition of Dimethyl sulfoxide (DMSO) ligand. The introduction of DMSO aids in better electronic oscillations in SCN ligand, leading to an improvement in NLO efficiency. The present study deals with the growth and characterization of pure and rare earth doped manganese mercury thiocyanate bis-dimethyl sulfoxide (MMTD), Lewis-base adducts of MMTC [4]. In the structure of MMTD, the hard $\mathrm{Mn}^{2+}$ ion is coordinated with the harder $\mathrm{N}$-(SCN) and $\mathrm{O}$-(DMSO) ligands, while the soft $\mathrm{Hg}^{2+}$ is coordinated with the softer S-(SCN) ligands. The $\mathrm{Hg}^{2+}$ ion is coordinated with four SCN S-atoms and is in a tetrahedral geometry [6].
The present investigation deals with the growth and characterization of pure, $\mathrm{La}^{3+}$ and $\mathrm{Nd}^{3+}$ doped Manganese mercury thiocyanate bis-dimethyl sulfoxide (MMTD) crystals, grown from a mixed solvent of water and DMSO.

\section{Experimental Methods}

Pure MMTC was synthesized by taking appropriate amount of $\mathrm{NH}_{4} \mathrm{SCN}$ $\mathrm{MnCl}_{2}$ and $\mathrm{HgCl}_{2}$. The chemicals were dissolved in double distilled water and stirred well for about 12 hours. The following is the reaction formula.

$$
4 \mathrm{NH}_{4} \mathrm{SCN}+\mathrm{MnCl}_{2}+\mathrm{HgCl}_{2} \rightarrow \mathrm{MnHg}(\mathrm{SCN})_{4}+4 \mathrm{NH}_{4} \mathrm{Cl}
$$

The seed crystals were obtained using dimethyl sulfoxide as a ligand to react with MMTC in a mixture of dimethyl sulfoxide and de-ionized water. The chemical reaction is:

$$
\mathrm{MnHg}(\mathrm{SCN})_{4}+2 \mathrm{C}_{2} \mathrm{H}_{6} \mathrm{OS} \rightarrow \operatorname{MnHg}(\mathrm{SCN})_{4}\left(\mathrm{C}_{2} \mathrm{H}_{6} \mathrm{OS}\right)_{2}
$$

After vigorous stirring, the $\mathrm{pH}$ of the solution was adjusted to be between 2 and 3 by slowly adding dilute $\mathrm{HCl}$, and then allowed to evaporate at room temperature.

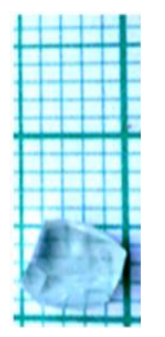

(a)

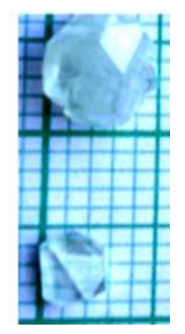

(b)

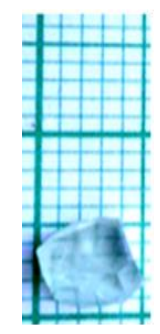

(c)
Fig. 1 Photographs of (a) pure, (b) $\mathrm{La}^{3+}$ and (c) $\mathrm{Nd}^{3+}$ doped MMTD single crystals

The same procedure is repeated for the growth of $\mathrm{La}^{3+}$ and $\mathrm{Nd}^{3+}$ doped MMTD crystals by substituting $2 \%$ of $\mathrm{Hg}$ by $2 \%$ of $\mathrm{La}^{3+}$ and $\mathrm{Nd}^{3+}$ respectively. Optically clear defect free and well-shaped crystals were 
chosen and used as seed crystals. The growth period ranged from 90-100 days. The photographs of the pure and doped MMTD crystals are shown in Fig. 1. The optical properties of the grown crystals have been studied by recording their FT-IR, FT-Raman spectra. Energy Dispersive X-ray analysis (EDAX) studies were also carried out.

\section{Results and Discussion}

\subsection{Single Crystal X-Ray Diffraction (XRD) Analysis}

From the single crystal XRD data, it is observed that the pure and doped MMTD crystals belong to the orthorhombic crystallographic system with the non-centrosymmetric space group $\mathrm{P} 2{ }_{1} 2_{1} 2_{1}$. The unit cell parameters of the pure and doped MMTD crystals are shown in Table 1. The calculated cell parameters match well with those obtained by Wang et al. [7].

Table 1 Comparison of unit cell parameters of pure, $\mathrm{La}^{3+}$ and $\mathrm{Nd}^{3+}$ doped MMTD single crystals

\begin{tabular}{llll}
\hline Lattice parameters & Pure MMTD & $\mathrm{La}^{3+}$ & $\mathrm{Nd}^{3+}$ \\
\hline $\mathrm{a}(\AA)$ & 8.6523 & 8.6605 & 8.6627 \\
$\mathrm{~b}(\AA)$ & 8.7043 & 8.7125 & 8.7232 \\
$\mathrm{c}(\AA)$ & 27.8750 & 27.8820 & 27.8937 \\
$\alpha=\beta=\gamma(\mathrm{deg})$ & 90 & 90 & 90 \\
Volume $(\AA \AA)$ & 2099.32 & 2103.82 & 2107.82 \\
Crystal system & Orthorhombic & Orthorhombic & Orthorhombic \\
Space group & $\mathrm{P} 2{ }_{1} 2_{1} 2_{1}$ & $\mathrm{P} 2{ }_{1} 2_{1} 2_{1}$ & $\mathrm{P} 2_{1} 2_{1} 2_{1}$ \\
\hline
\end{tabular}

\subsection{Optical Absorption Studies}

It is well known that an efficient NLO crystal has an optical transparency at lower cut-off wavelengths between 200 and $400 \mathrm{~nm}$ [8]. It is observed from the spectra (Fig. 2) that pure and doped MMTD crystals have a wide transmission window. The UV cut off wavelengths of the pure, $\mathrm{La}^{3+}$ and $\mathrm{Nd}^{3+}$ doped MMTD crystals are observed to be $374 \mathrm{~nm}, 348 \mathrm{~nm}$ and 354 $\mathrm{nm}$ respectively. The results agree well with the reported values [9]. Hence the doped samples of MMTD are found to be superior than compared to their parent MMTD. In the entire visible region, the optical absorption spectra are flat and constant. This wide transmission range in the entire visible region is a desirous useful property for opto-electronic applications.

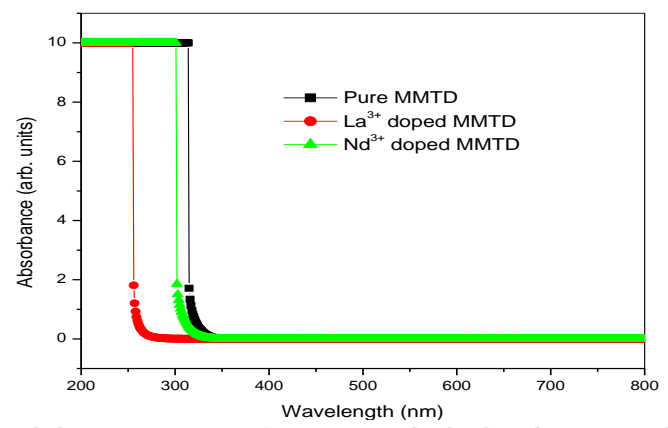

Fig. 2 Optical absorption spectra of pure, $\mathrm{La}^{3+}$ and $\mathrm{Nd}^{3+}$ doped MMTD single crystals

\subsection{FT-IR Studies}

Fig. 3 shows the FT-IR transmission spectra of the pure, $\mathrm{La}^{3+}$ and $\mathrm{Nd}^{3+}$ doped MMTD crystals. The main IR spectral data of pure and doped MMTD with MMTC and DMSO are presented in Table 2. It is well known that the $\mathrm{C}-\mathrm{N}$ stretching vibration often lies above $2100 \mathrm{~cm}^{-1}$, the C-S stretching vibration lies between 860 and $780 \mathrm{~cm}^{-1}$ (N-bonding) or between 720 and $690 \mathrm{~cm}^{-1}$ (S-bonding) and SCN bending vibration lies near $480 \mathrm{~cm}^{-1}(\mathrm{~N}-$ bonding) or $420 \mathrm{~cm}^{-1}$ (S-bonding) $[10,11]$. The strong band observed at $2100 \mathrm{~cm}^{-1}$ which is attributed to stretching vibration of C-N in MMTD, is now shifted to $2081 \mathrm{~cm}^{-1} / 2117 \mathrm{~cm}^{-1}$ due to the presence of $\mathrm{La}^{3+} / \mathrm{Nd}^{3+}$ ions. The weak and sharp band at $756 \mathrm{~cm}^{-1}$ which is assigned to the C-S stretching in MMTD is now observed to be shifted to $751 \mathrm{~cm}^{-1}$ due to the presence of $\mathrm{Nd}^{3+}$ ions. The $\mathrm{S}-\mathrm{O}$ vibration frequencies in pure and doped MMTD are now shifted to lower values when compared to that of DMSO. This could be attributed to the coordination of $\mathrm{O}$ atoms with the Mn atoms, which cause weaker bonds between $\mathrm{O}$ and $\mathrm{S}$ in the coordinated DMSO molecule [9]. The stretching and bending modes of $\mathrm{C}-\mathrm{H}$ in pure and rare earth doped MMTD are also found to be shifted from the frequencies of free DMSO. This confirms that the molecular structure of DMSO in MMTD is different from that of the free DMSO, which can be attributed to the fact that the DMSO molecule combines with $\mathrm{Mn}$ as a monodentate ligand through $\mathrm{O}$ atom.
Table 2 Comparison of FT-IR bands of pure and doped MMTD single crystals with DMSO and MMTC

\begin{tabular}{llllll}
\hline Assignments & $\begin{array}{l}\text { DMSO } \\
\left(\mathrm{cm}^{-1}\right)\end{array}$ & $\begin{array}{l}\text { MMTC } \\
\left(\mathrm{cm}^{-1}\right)\end{array}$ & $\begin{array}{l}\text { MMTD } \\
\left(\mathrm{cm}^{-1}\right)\end{array}$ & $\begin{array}{l}\mathrm{La}^{3+} \\
\left(\mathrm{cm}^{-1}\right)\end{array}$ & $\begin{array}{l}\mathrm{Nd}^{3+} \\
\left(\mathrm{cm}^{-1}\right)\end{array}$ \\
\hline CN stretching & --- & 2118 & 2120 & 2124 & 2126 \\
CS stretching & --- & 778 & 756 & 756 & 751 \\
SCN bending & --- & 463 & 462 & 462 & 462 \\
2SCN bending & --- & 896, & 931, & 922, & 928, \\
& & 939 & 990 & 991 & 992 \\
CH stretching & 2913, & 2905, & 2862, & 2862, & 2879, \\
& 2999 & 3009 & 2915 & 2915 & 3000 \\
SO stretching & 1050 & --- & 1012, & 1032 & 1013, \\
& & & 1032 & & 1030 \\
CH bending & 1436, & --- & 1408, & 1409, & 1414, \\
& 1406,1314 & & 1247 & 1252 & 1316 \\
\hline
\end{tabular}

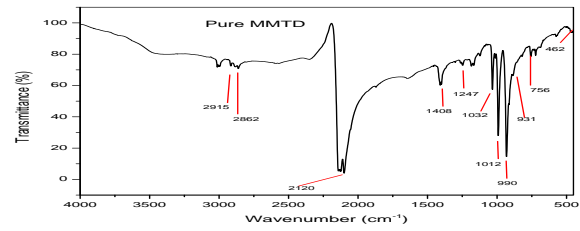

(a)

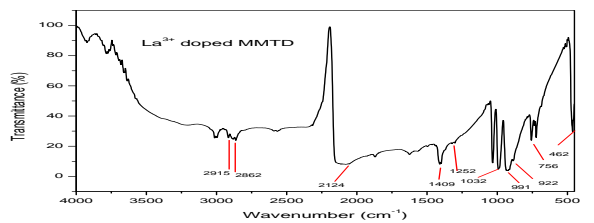

(b)

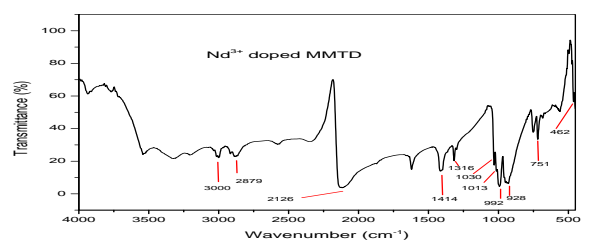

(c)

Fig. 3 FT-IR spectra of (a) pure, (b) $\mathrm{La}^{3+}$ and (c) $\mathrm{Nd}^{3+}$ doped MMTD single crystals

\subsection{FT-Raman Studies}

Fig. 4 shows the FT-Raman spectra of the pure and doped MMTD crystals. The observed bands along with their vibrational assignments are listed in Table 3.

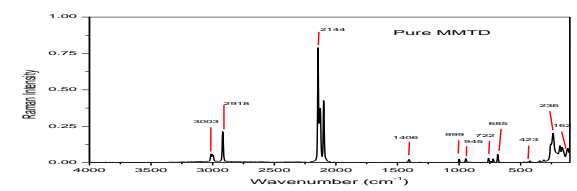

(a)

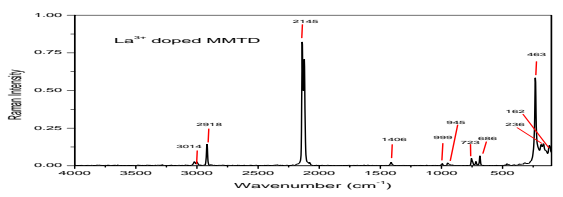

(b)

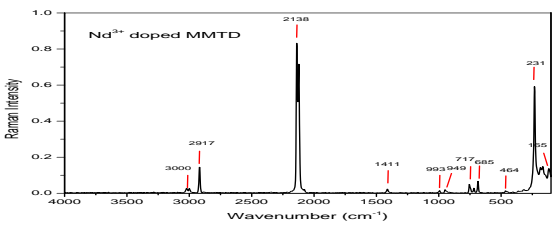

(c)

Fig. 4 FT-Raman spectra of (a) pure, (b) $\mathrm{La}^{3+}$ and (c) $\mathrm{Nd}^{3+}$ doped MMTD single crystals 
Table 3 Comparison of FT-Raman spectral assignments of pure and doped MMTD single crystals with MMTC

\begin{tabular}{lllll}
\hline Assignments & MMTC $\left(\mathrm{cm}^{-1}\right)$ & MMTD $\left(\mathrm{cm}^{-1}\right)$ & $\mathrm{La}^{3+}\left(\mathrm{cm}^{-1}\right)$ & $\mathrm{Nd}^{3+}\left(\mathrm{cm}^{-1}\right)$ \\
\hline CN stretching & 2146 & 2144 & 2145 & 2138 \\
CS stretching & 779 & 685,722 & 686,723 & 685,717 \\
SCN bending & 447 & 423 & 463 & 464 \\
2SCN bending & 898,940 & 945,999 & 945,999 & 949,993 \\
CH stretching & 2901,2932 & 2918,3003 & 2918,3014 & 2917,3000 \\
CH bending & 1461 & 1406 & 1406 & 1411 \\
SHgS bending & 160 & 162 & 162 & 165 \\
NMnN bending & 231 & 236 & 236 & 231 \\
\hline
\end{tabular}

\subsection{EDAX Analysis}

The exact weight percentages of $\mathrm{La}^{3+}$ and $\mathrm{Nd}^{3+}$ ions present in the doped crystals were determined using EDAX analysis. The results show that only $0.48 \%$ of $\mathrm{La}^{3+}$ and $0.69 \%$ of $\mathrm{Nd}^{3+}$ were present in the respective samples out of $2 \%$ of the dopant (Fig. 5).

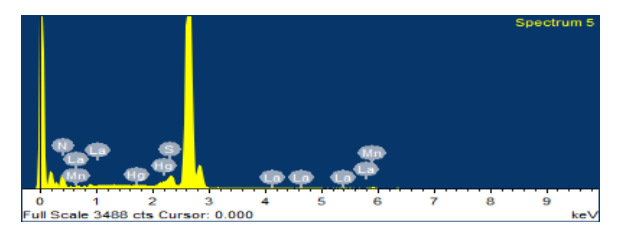

(a)

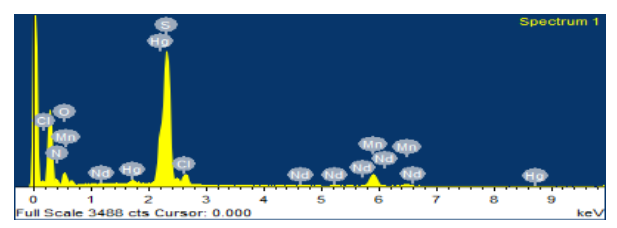

(b)

Fig. 5 EDAX spectra of (a) $\mathrm{La}^{3+}$ and (b) $\mathrm{Nd}^{3+}$ doped MMTD single crystals

\subsection{Nonlinear Optical (NLO) Studies}

For a laser input of $6.2 \mathrm{~mJ}$, second harmonic signals of $532 \mathrm{~nm}$ were produced at $91.66 \mathrm{~mW}, 2273.16 \mathrm{~mW}, 2340.07 \mathrm{~mW}$ and $2384.99 \mathrm{~mW}$ for urea, pure, $\mathrm{La}^{3+}$ and $\mathrm{Nd}^{3+}$ doped MMTD crystals respectively. The experimental data confirms the second harmonic efficiencies of the pure, $\mathrm{La}^{3+}$ and $\mathrm{Nd}^{3+}$ doped MMTD crystals to be nearly 24.8, 25.53 and 26.02 times higher than that of urea. Thus the SHG efficiencies of pure and doped MMTD crystals are very much higher than CMTC, CMTD and BTCC of organometallic family $[12,13]$, as well as the conventional laser materials like KDP, LAP and BBO [14, 15].

\section{Conclusion}

The growth of single crystals of MMTD with rare earth substitution is achieved successfully by slow evaporation technique. The structure of the grown crystals and their compositions were confirmed by single crystal
XRD and EDAX elemental analysis. The second harmonic efficiencies of the pure, $\mathrm{La}^{3+}$ and $\mathrm{Nd}^{3+}$ doped MMTD crystals are found to be 24.8, 25.53 and 26.02 times higher than that of urea. The good optical properties combined with very high SHG efficiency suggest that MMTD crystals with rare earth substitution can be exploited for future application in photonic device fabrications.

\section{Acknowledgement}

The authors acknowledge the University Grants Commission (UGC), India for funding this research work. The authors are also grateful to Dr. Babu Varghese (SAIF, IIT, Chennai), for providing single crystal XRD facility. Special thanks to Dr. Sandhya Cole for the moral support and cooperation.

\section{References}

[1] M. Selvapandiyan, S. Sudhakar, P. Sundaramoorthi, Crystal growth, structural spectral and mechanical studies of pure and KI doped ZTS single crystals, J. Alloys Compd. 523 (2012) 25-29.

[2] Y. Wu, W. Bensch, Synthesis, crystal structures and optical properties of $\mathrm{NaCdPnS}_{3}(\mathrm{Pn}=\mathrm{As}, \mathrm{Sb})$, J. Alloys Compd. 511 (2012) 35-40.

[3] R.G. Pearson, Hard and soft acids and bases, J. Am. Chem. Soc. 85 (1963) 3533 3548.

[4] X.Q. Wang, D. Xu, M.K. Lu, D.R. Yuan, G.H. Zhang, F. Qmeng, et al., Investigation of bimetallic thiocyanates belonging to ABTC structure type: $\mathrm{ZnCd}(\mathrm{SCN})_{4}$ and $\mathrm{AHg}(\mathrm{SCN})_{4} \quad(\mathrm{~A}=\mathrm{Zn}, \mathrm{Cd}, \mathrm{Mn})$ as nonlinear optical crystal materials, Cryst. Res. Technol. 36 (2001) 73-84.

[5] K. Nakamoto, IR and Raman spectra of inorganic and coordination compounds, Wiley Inter-Science, New York, 1977.

[6] X.Q. Wang, D. Xu, M.K. Lu, D.R. Yuan, S.X. Xu, Crystal growth and characterization of the organometallic nonlinear optical crystal: manganese mercury thiocyanate (MMTC), Mater. Res. Bull. 36 (2001) 879-887.

[7] X.Q. Wang, W.T. Yu, D. Xu, M.K. Lu, D.R. Yuan, Poly [[bis(dimethyl sulfoxide$O$ )tris(thiocyanato- $N$ )manganese(II)]- $\mu$-thiocyanato- $N: S$-mercury(II)], Acta Cryst. C 56 (2000) 418-420.

[8] Y. Le Fur, R. Masse, M.Z. Cherkaoui, J.F. Nicoud, Crystal structure of 1-ethyl-2, 6-dimethyl-4(1 H)-pyridinone, trihydrate: a potential nonlinear optical crystalline organic material transparent till the near ultraviolet range, $\mathrm{Z}$. Kristallogr. 210 (1995) 856-860.

[9] X.Q. Wang, D. Xu, M.K. Lu, D.R. Yuan, S.X. Xu, S.Y. Guo, G.H. Zhang, J.R. Liu, Crystal growth and characterization of a novel organometallic nonlinear optical crystal: $\mathrm{MnHg}(\mathrm{SCN})_{4}\left(\mathrm{C}_{2} \mathrm{H}_{6} \mathrm{OS}\right)_{2}$, J. Cryst. Growth 224 (2001) 284-293.

[10] K. Nakamoto, Infrared and raman spectra of inorganic and co-ordination compounds, 3rd Ed., Wiley, New York, 1978.

[11] R.M. Silverstein, F.X. Webster, Spectroscopic identification of organic compounds, $6^{\text {th }}$ Ed., Wiley, New York, 1998.

[12] S. Selvakumar, J. Packiam Julius, S.A. Rajasekar, A. Ramanand, P. Sagayaraj, Microhardness, FTIR and transmission spectral studies of $\mathrm{Mg}^{2+}$ and $\mathrm{Zn}^{2+}$ doped nonlinear optical BTCC single crystals, Mater. Chem. Phys. 89 (2005) 244-248.

[13] S.Y. Guo, D.P. Yang, W.T. Yu, M.K. Lu, D.R. Yuan, Z.H. Yag, et al., A novel nonlinear optical complex crystal with an organic ligand coordinated through an o atom: tetrathiocyanatocadmiummercury-dimethyl sulfoxide, Cryst. Res. Technol. 36 (2001) 609-614.

[14] B. Narayana Moolya, A. Jayarama, M.R. Sureshkumar, S.M. Dharmaprakash, Hydrogen bonded nonlinear optical $\gamma$-glycine: crystal growth and characterization, J. Cryst. Growth 280 (2005) 581-586.

[15] A. Pricilla Jeyakumari, J. Ramajothi, S. Dhanuskodi, Structural and microhardness studies of a NLO material-bisthiourea cadmium chloride, J. Cryst. Growth. 269 (2004) 558-564.

About the Conference: "International Conference on Nanomaterials (ICAN) - 2018" has been organized by Dr. G. Ramalingam, ICAN2018 Organizing Secretary, Assistant Professor, Department of Nanoscience and Technology, Alagappa University, Karaikudi, TN, India at his designated venue on $26^{\text {th }} \& 27^{\text {th }}$ February 2018. 